\title{
Measuring Voluntary Control Over Hallucinations: The Yale Control Over Perceptual Experiences (COPE) Scales
}

Catalina Mourgues, Ph.D. ${ }^{1}$, Allison Hammer ${ }^{1}$, Victoria Fisher ${ }^{1}$, Eren Kafadar ${ }^{1}$, Brittany Quagan ${ }^{1}$, Claire Bien $^{1}$, Hale Jaeger ${ }^{1}$, Rigi Thomas ${ }^{2}$, Ely Sibarium ${ }^{1}$, Alyson M. Negreira, Ph.D. ${ }^{3}$, Elif Sarisik, M.D. ${ }^{4}$, Vasishta Polisetty, M.D. ${ }^{5}$, Hatice Nur Eken ${ }^{6}$, Ayyub Imtiaz, M.D. ${ }^{7}$, Halsey Niles, M.D. ${ }^{1}$, Andrew D. Sheldon, M.D., Ph.D. ${ }^{1}$, Albert R. Powers, M.D., Ph.D. ${ }^{1 *}$

1. Yale University School of Medicine, New Haven, CT, USA

2. Southwest College of Naturopathic Medicine, AZ, USA

3. Cincinnati Veterans Affairs Medical Center, Cincinnati, Ohio

4. Istanbul Faculty of Medicine, Istanbul University, Istanbul, Turkey

5. Dept. of Psychiatry, All India Institute of Medical Sciences, New Delhi, India

6. Vanderbilt University School of Medicine, Nashville, TN, USA

7. Faculty of Medicine, Health Sciences Center, Kuwait University, Kuwait

*Correspondence should be addressed to: albert.powers@yale.edu

Office: 203.974 .7329

The Connecticut Mental Health Center, Rm S109

34 Park Street

New Haven, CT, 06517

United States

Words in abstract: 250

Words in main body of manuscript: 3481

Figures: 4 


\begin{abstract}
Auditory verbal hallucinations (AVH) frequently cause significant distress and dysfunction, and may be unresponsive to conventional treatments. Some voice-hearers report an ability to fully control the onset and offset of their AVH, making them significantly less disruptive. Measuring and understanding these abilities may lead to novel interventions to enhance control over AVH.
\end{abstract}

52 voice-hearers participated in the pilot study. 318 participants with frequent AVH participated in the validation study. A pool of 59 items was developed by a diverse team including voice-hearers and clinicians. After the pilot study, 35 items were retained. Factorial structure was assessed with exploratory (EFA, $n=148)$ and confirmatory $(C F A, n=170)$ factor analyses. Reliability and convergent validity were assessed using a comprehensive battery of validated phenomenological and clinical scales.

CFA supported two factors for a Methods of Control Scale ( 5 items each, average $\omega=.87$ ), and one factor for a Degree of Control Scale ( 8 items, average $\omega=.95$ ). Correlation with clinical measures supported convergent validity. Degree of control was associated with positive clinical outcomes in voice-hearers both with and without a psychosis-spectrum diagnosis. Degree of control also varied with quality of life independently of symptom severity and AVH content.

The Yale COPE Scales are the first measure of voice-hearers' control over AVH and exhibit sound psychometric properties. Results demonstrate that the capacity to voluntarily control AVH is independently associated with positive clinical outcomes. Reliable measurement of control over AVH will enable future development of interventions meant to bolster that control. 


\section{Introduction}

Although auditory hallucinations may be a prominent part of psychotic illness, many voice-hearers never develop the need to seek help for their experiences ${ }^{1-3}$. Individuals' beliefs and patterns of interacting with their voices predict the severity of resulting functional impairment ${ }^{4-7}$. Voluntary control over voicehearing experiences has been strongly associated with the level of distress and functional impairment associated with these experiences ${ }^{8}$. Voluntary control over voice-hearing experiences, defined here as the ability to intentionally influence the timing, frequency, or intensity of voice-hearing experiences, has been described as taking a variety of forms. These abilities range from performing activities that impact voicehearing that are unrelated to voice-hearing (termed non-engagement-based approaches such as hearing music) $)^{9,10}$ to directly controlling the onset and/or offset of voice-hearing episodes (termed engagementbased approaches $)^{11-14}$. This heterogeneity poses a significant challenge to the characterization of the psychological and biological processes underlying the development of control over voice-hearing experiences. For example, non-engagement-based approaches, characterized by diverting attention away from voice-hearing, are likely to be subserved by very different neural mechanisms from engagementbased approaches, which directly manipulate the occurrence of voice-hearing events themselves ${ }^{8,15,16}$. The ability to measure these subtypes reliably is crucial for the identification of their neural substrates and the development of new treatments based upon this advancing knowledge.

Help-seeking and non-help-seeking voice-hearing populations also differ on several factors that could impact the development of control ${ }^{14,17-20}$. Despite these differences, recent qualitative work suggests that the ability to exert control over voice-hearing experiences is often developed in very similar stages regardless of help-seeking status ${ }^{15}$. This finding is particularly promising because it implies that control over voice-hearing experiences is not wholly dependent upon fixed differences in cognitive abilities, distress, or phenomenological characteristics ${ }^{1,4,15,19,21}$, but may be fostered nonetheless. 
Although control over voice-hearing experiences may be important to prediction of clinical outcomes and novel treatment development, there are very few measures to directly characterize control over voicehearing in detail ${ }^{22}$. Non-clinical voice-hearers' experiences and methods used to exert control have garnered interest within the mental health field in recent years ${ }^{23-25}$. However, there are no tools currently available to specifically assess the level, nature, and progression of control over voice hearing experiences. Existing tools consist of single clinician-rated items on comprehensive scales of psychotic symptomatology such as the Psychotic Symptom Rating Scale (PSYRATS-AH) ${ }^{17,26}$ and Chicago Hallucination Assessment Tool (CHAT) ${ }^{27}$, as well as certain items on the BAVQ-R that focus on the relationship between the voice-hearer and their voices but do not delineate control abilities in a clinically useful manner.

With the extensive involvement of voice-hearers, we have developed the first scales specifically designed to measure the types of control individuals exhibit and their overall ability to exert this control. Here, we present data demonstrating the initial validity and reliability of the Yale Control Over Perceptual Experiences (COPE) Scales and their relationships to clinically-relevant aspects of functioning in voicehearing populations.

\section{Methods}

\section{Item development and piloting}

Following recent qualitative work ${ }^{15}$ and a review of relevant extant scales, an initial pool of 59 items capturing degree and methods of control was developed by a multidisciplinary team including mental health professionals, representatives of voice-hearer support groups, and spiritual communities with a high prevalence of voice-hearing experiences. Items used a 7-point Likert scale ranging from Never (1) to Always (7), reflecting the frequency of a particular experience when the voices first started and at the present time (Figure 1; Table S1). Initial item reduction was conducted with feedback from a pilot sample of 52 voice-hearers who had developed varying degrees of control by self-report (see 
Supplemental Material for sample details). Cognitive interviews ${ }^{28}$ were conducted to obtain feedback on the items' simplicity, clarity, and phrasing. As a result, the wording of several items was changed to better reflect voice-hearers' experiences (see Supplemental Material for examples). 35 items were selected for the final COPE Scales. 21 of these captured Methods of Control, including 12 items to measure engagement-based and 9 items to measure non-engagement-based approaches. Overall Degree of Control over the voice-hearing experiences was captured by the remaining 14 items. Three independent raters consistently assigned items to the correct corresponding scale (ICC $=.720)$.

\section{$\underline{\text { Scale development and psychometrics }}$}

\section{Participants}

All procedures were approved by the Yale University Institutional Review Board / Human Interest Committee. A sample of 318 participants was selected from a total of 1134 participants enrolled in the ongoing Yale COPE Project (https://www.spirit.research.yale.edu/). Selection was based on completion of required scales, and presence of voice-hearing experiences meeting minimum frequency (at least once per month) and recency (within the last 6 months) thresholds. Participants younger than 18 and older than 65 were excluded, as were those with self-reported cognitive, neurological, or seizure disorders, and those reporting use of non-prescription drugs or alcohol during study completion. All participants completed an extensive online battery collecting demographic and clinical information in addition to behavioral data on computerized perceptual and cognitive tasks, coordinated through Yale's instantiation of Research Electronic Data Capture (REDCap@Yale) $)^{29,30}$.

Data quality control was ensured by assessing response consistency on key items across all scales. The Miller Forensic Assessment of Symptoms Test (M-FAST) $)^{31,32}$ and computerized binary Scale for Auditory Speech Hallucinations (cbSASH) ${ }^{33,34}$ were used to flag responses for internal inconsistency and potential for malingering. If participants were flagged for any reason, a clinician from the research team (authors BQ, ES, and AH) conducted one-on-one online video interviews to ensure singular participation, 
clarity of responses, and data integrity prior to compensation and data inclusion. From the initial 327

selected participants, 74 were flagged. After a second analysis of their responses and/or interview, 9 failed to comply with the required interview and their data were excluded from final analysis.

\section{Measures}

Convergent validity related to beliefs and distress due to voice-hearing was assessed using the following instruments: the Beliefs About Voices Questionnaire (BAVQ-R) ${ }^{35,36}$, Launay-Slade Hallucination Scale $(\text { LSHS-R })^{37}$, and the Peters Delusions Inventory (PDI-21) ${ }^{35}$. The intensity and phenomenology of voicehearing experiences were recorded using the Chicago Hallucination Assessment Tool (CHAT) ${ }^{27}$ and Computerized Binary Scale for Auditory Speech Hallucinations (cbSASH) ${ }^{33}$. The White Bear Suppression Inventory (WBSI) ${ }^{38}$, Daily Stress Inventory (DSI) ${ }^{39}$, and the Quality of Life Enjoyment and Satisfaction Questionnaire-Short Form (QOL) ${ }^{40}$ were included to assess cognitive and daily functioning. Finally, the Personality Disorders Questionnaire (SCID-II) and Patient Health Questionnaire-9 (PHQ-9) ${ }^{41}$ assessed for the presence of characterological and mood pathology. Clinical interviews were conducted on a subsample of participants to assess for consistency of self-reported and clinical diagnosis. Interviews consisted of a full Mini International Neuropsychiatric Interview (MINI) for Psychotic Disorders Studies 7.0.2 along with one item from Auditory Hallucination Rating Scale (AHRS) ${ }^{42}$ and another from Psychotic Symptom Rating Scales (PSYRATS) ${ }^{17}$ to assess the degree of control over the voice hearing experiences. Results demonstrated high agreement of self-reported and clinical diagnosis $(\mathrm{N}=32 ; \kappa=$ 0.683; 84\% agreement; see Table $\mathbf{S 2}$ for demographics of interviewed sample).

\section{Analysis}

The sample was randomly split into 2 subsamples. One subsample $(\mathrm{n}=148)$ was used for exploratory factor analysis $(\mathrm{EFA})$ and the other $(\mathrm{n}=170)$ was reserved for subsequent confirmatory factor analysis (CFA) $(n=170)$. No significant differences between the two samples were found on any demographic or clinical variables (Tables 1 and S2). Item responses were treated as ordinal variables ${ }^{43}$. Polychoric 
matrices of correlations were generated for factorial analyses. Diagonally-weighted least squares $(D W L S)^{44}$ were used as estimation methods for EFA and CFA. Items were then removed from the scales based on their complexity/cross-loading (com $>1.3$ ), factor loadings $(\lambda<0.4)$, and internal consistency

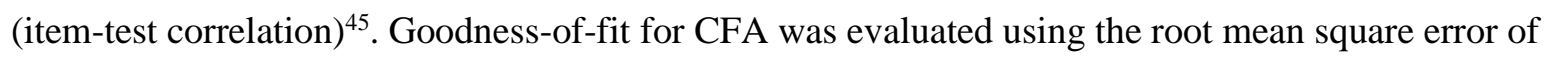
approximation (RMSEA < 0.08), the comparative fit index (CFI > 0.95), and the Tucker-Lewis index $(\mathrm{TLI}>0.95)^{46}$. Internal consistency was assessed using the omega coefficient $(\omega)^{47}$. Measurement Invariance (MI) with the complete sample was conducted between participants that reported a psychosisspectrum diagnosis $(n=72)$ and those without such a diagnosis $(n=246)$. Concurrent validity was assessed by analysing the matrix of correlations between the COPE scales and the above measures. Analyses were performed on R using the packages coefficient alpha (v. 0.5), Lavaan (v. 0.6- 5), mediation (v. 4.5.0), and Polycor (v. 0.7-10).

\section{Results}

Sample description

Table $\mathbf{S 2}$ provides a full description of sample demographics. The sample was varied in terms of level of functioning and rates of self-reported mental illness (Table 1). The vast majority (88.6\%) reported having completed some post-secondary education, but $41.82 \%$ reported being currently unemployed, and only $31 \%$ reported working more than 30 hours per week. Nearly half (47.5\%) of participants reported having a mental health diagnosis, with $28.62 \%$ reporting having 2 or more diagnoses. $22.64 \%$ reported having received a psychosis-spectrum diagnosis (schizophrenia, psychosis, bipolar I, bipolar II, bipolar unspecified and schizoaffective disorders). The most common diagnoses endorsed were anxiety (16.98\%), depression (15.09\%), and PTSD (7.23\%).

The SCID-II self-report questionnaire was used to screen for potential character pathology. The most common positive screen (36.16\%) was for potential schizotypal personality disorder (Table 1). Nearly half $(45.3 \%)$ met the threshold for odd beliefs (PDI score $>8)^{48}$, and 30.5\% reported having visual 
hallucinations in addition to auditory hallucinations. Nearly all (94.03\%) reported having heard voices within the last month; the remaining 5.97\% had heard voices within the last 6 months. Frequency of voice-hearing ranged from daily (39.94\%) to weekly (32.39\%) to monthly $(27.67 \%)$.

The majority of participants endorsed robust voice-hearing experiences: $67.0 \%$ reported that the voices were clear like a sound, $64.5 \%$ that the voices had conversations, and $65.5 \%$ heard more than one voice. Affective response to the voices and attribution varied: $56.4 \%$ reported that they were not bothered by the voices, $45.5 \%$ identified the voices as those of spirits and $53.1 \%$ as those of deceased people, while $17.4 \%$ indicated that they hear voices because of their mental illness. Figure 3A outlines additional phenomenological characteristics of the sample's voice-hearing experiences.

\section{Item reduction}

EFA and CFA were conducted independently for each time period. The numbers of factors were determined using parallel analysis, scree plots, and Kaiser's rule (eigenvalues $>1$ ) (Figure 2A). Parallel analysis suggested use of 3 factors while the scree plots suggested 2 factors for the Methods of Control Scale at both time points ( 21 items). Testing of the 3 -factor model showed that the third factor had only 5 items, and only 2 without significant cross-loadings. Given these results, a 2-factor model was chosen. After EFA, 11 items were removed because of: a) factor loadings lower than 0.4 (items 13 and 28); b) significant cross-loading (items 9, 10, 14, and 22); and c) redundancy of content with no impact on internal consistency (items 1, 4, 5, 17, and 35). A similar procedure was followed with the Degree of Control Scale (14 items). The parallel analysis, scree plot, and Kaiser's rule suggested a solution of only one factor. All the items of the Degree of Control Scale performed appropriately $(\lambda \geq .04)$. After EFA, 6 items were dropped because of redundancy of content with no impact on internal consistency (see Table S3). The final scale to measure Methods of Control was composed of 10 items ( 5 for Engagement- and 5 for Non-Engagement-Based Approaches). The Degree of Control Scale included 8 items. 


\section{Reliability and Latent Structure}

CFA conducted with the remaining 170 participants showed good fit indices for both the Methods of Control and Degree of Control scales (Figures 1C-D). Correlations between Engagement- and NonEngagement-Based factors supported a distinction between these factors $\left(r_{(170) \text { present }}=-0.294, p<.001\right.$, $\left.r_{(170) \text { past }}=-0.105, p=\mathrm{ns}\right)$. Internal consistency measures for Engagement-Based and Non-Engagement-

Based approaches were excellent (mean $\omega_{\text {non-engagement-based (present and past) }}=0.88$ and mean $\omega_{\text {engagement-based(present }}$ and past $)=0.85)$, as was internal consistency for the Degree of Control $\left(\right.$ mean $\left._{\text {present and past }}=0.95\right)$.

\section{Convergent and Discriminant Validity}

No instruments exist to measure degree and methods of control over voice-hearing experiences. Several measures related to phenomenology and clinical status as well as single items pertaining to control were included to assess convergent and discriminant validity (See Table 2). Voice-hearing experiences have been associated with higher propensity toward odd beliefs (PDI), other unusual perceptual experiences (LSHS-R; CHAT), and unwanted thoughts (WBSI). Additionally, beliefs held about the malevolence and omnipotence of voices (BAVQ-M, BAVQ-O) as well as resistance to voices (BAVQ-R) have been related to distress, impairment, and likelihood of obtaining a diagnosis in voice-hearers ${ }^{4,5,19}$. Consistent with these studies, Degree of Control and Engagement-Based Approaches were negatively and significantly associated with distress due to delusions (PDI Distress), hallucination severity (CHAT), intrusive thoughts (WBSII, WBSIS, WBSID), beliefs about voices' malevolence and omnipotence (BAVQ-M, BAVQ-O), and resistance to voices (BAVQ-R). These scales were positively and significantly correlated with beliefs in voices' benevolence (BAVQ-B) and engagement with the voices (BAVQ-E). The opposite pattern was generally observed for use of Non-Engagement-Based approaches. Hallucination frequency was negatively correlated with use of engagement-based approaches $\left(r_{(295) p a s t}=-\right.$ $\left..180, r_{(295) \text { present }}=-.276, p s<.01\right)$ and degree of control exhibited $\left(r_{(295) \text { past }}=-.180, r_{(295) \text { present }}=-.253\right.$, ps $<$ $.01)$, but not with use of non-engagement-based approaches. Finally, as was expected, the use of 
engagement-based approaches was highly correlated with degree of control $\left(r_{(318) \text { past }}=0.812, r_{(318) \text { present }}=\right.$ $0.875, p s<0.001)$.

\section{Consistency self-reported and clinician-rated control}

Semi-structured interviews were conducted with thirty-two participants. This sub-sample was similar to the complete sample on voice frequency and recency, degree of control over the voices, and self reported psychosis-spectrum illness (Table S2). Two additional clinician-rated items were administered during the interview to capture participants' abilities to control their voice-hearing experiences. Clinicians were blind to the participants' self-report ratings for all the questionnaires administered. Clinician ratings of (1) how frequently participants felt in control of the voices (Cronbach $\alpha=.761)$ and (2) how much effort was required to ignore the voices (Cronbach $\alpha=.704$ ) were consistent with self-reported degree of control. All correlations were stronger for the present $\left(r_{(32) \text { engagement present/(1) }}=.737, r_{(32) \text { engagement present/(2) }}=.540\right.$, $\left.r_{(32) \text { Degree control present/(1) }}=.795, r_{(32) \text { Degree of control present/(2) }}=-.553, p s<.001\right)$, than for the past $\left(r_{(32) \text { engagement past/(1) }}\right.$ $\left.=.268, r_{(32) \text { engagement past } /(2)}=-.328, p=\mathrm{ns}, r_{(32) \text { Degree control past } /(1)}=.427, r_{(32) \text { Degree of control } /(2)}=-.370, p<.05\right)$.

\section{Clinical relevance of the Yale COPE Scale}

The COPE scales demonstrated good internal consistency for both groups and at both time points (see Table S5). The pattern of z-order correlations between the scales between both groups on the COPE scales was similar except for the relationship between the frequency of use of engagement-based versus non-engagement-based approaches at the present $\left(r_{(246) \text { no diagnosis }}=-.236, p<.001 ; r_{(72) \text { diagnosis }}=-.091, p=\right.$ ns; Figures 3B-C). Participants with a psychosis-spectrum diagnosis used engagement-based approaches less frequently $\left(t_{(134.661) \text { present }}=3.88, t_{(175.889) \text { past }}=2.984, p<.005\right)$, reported a lower degree of control overall $\left(t_{(144.119) \text { present }}=4.760, t_{(201.688) \text { past }}=5.012, p<.001\right)$ and a higher frequency of the use of nonengagement-based approaches at the present $\left(t_{(316) \text { present }}=4.930, p<0.001\right)$. Interestingly, no differences 
were found in the frequency of use of non-engagement-based approaches between the groups when the voices started (see Figures 3C-D).

Lastly, we examined relationships between the COPE scales and functional status. Significant and positive correlations were observed between use of both Engagement-Based Approaches and Degree of Control scores and quality of life, educational level, and working hours per week (Table 2). By contrast, use of non-engagement-based approaches was significantly and negatively related to all of these measures. Importantly, associations between engagement-based approaches $\left(r_{Q O L(124)}=.248, p=.005\right.$; $\left.r_{w o r k(124)}=.237, p=.008\right)$ and degree of control at the present $\left(r_{Q O L(124)}=.240, p=.007 ; r_{\text {work }(124)}=.188, p=\right.$ .035) with these outcomes remained significant after controlling for both malevolence beliefs (BAVQ-M) and distress due to delusions (PDI Distress). A simple mediation model (Figure 4) demonstrates that Degree of Control partially mediates the relationship between beliefs about voices' malevolence and quality of life (Sorvel's test, $z=-1.992, p=.046$ ). Indirect effects were also significant: using 5,000 bootstrapped samples, the unstandardized indirect effect was 0.84 with a $95 \%$ confidence interval of [$.1216,-.0132]$.

\section{Discussion}

The current study presents the first self-report measures of control over voice-hearing experiences, evaluates their psychometric properties, and provides initial support for their construct validity.

The ability of voice-hearers to function is predicted by many factors, including psychiatric comorbidities, beliefs about voices, and the content of what is heard. As we $\mathrm{e}^{8,15}$ and others ${ }^{19,49-51}$ have argued, control over voice-hearing experiences is another, potentially modifiable determinant of functioning. Here, we demonstrate that the impact of control over voice-hearing experiences extends beyond these other factors. We show that different methods of achieving control over voice-hearing experiences exhibit differential patterns related to functioning and quality of life--namely, that approaches based in engagement with 
voices are associated with higher quality of life and overall functioning. This supports findings that tie beliefs about voices and engagement styles to distress and clinical status ${ }^{4,19,36,52}$ and extends these findings to control over voice-hearing experiences, which may be a key benefit arising from these beliefs and engagement styles ${ }^{53}$.

One key feature of the Yale COPE Scales is their ability to quantify control abilities and characterize the methods used to exert them without the use of comprehensive structured interviews and clinician ratings. The ability of the scales to differentiate between methods of exerting control and how these abilities change over time from the participant's perspective is crucial for development of interventions meant to enhance them. Applied prospectively, the scales may aid in the prediction of conversion to psychosis in those at clinical high risk for psychosis. Individuals in this group often present with perceptual abnormalities that, while at times distressing, do not themselves predict conversion ${ }^{54}$. Precise measurement of control abilities also allows for identification of predictors of control over voice-hearing experiences. Static (e.g., trauma history, cognitive capacity) and dynamic (e.g., daily stress, medication dose) factors may each contribute to the degree and trajectory of control development, and their identification will be crucial for recognition and amelioration of barriers to control development. Creation of therapies specifically meant to foster control for those in the earliest phases of psychosis may allow for the effective curtailment of functional decline often accompanying voice-hearing in the clinical setting.

Recent work in neurofeedback methods for auditory hallucinations highlights these methods' potential for improving functioning in voice-hearers by altering activity in the auditory cortex ${ }^{51,55,56}$. One potential outcome of these approaches may be enhanced control over hallucinations ${ }^{49}$, speaking to the potential involvement of auditory cortices in the exertion of control over voice-hearing experiences. The work presented here may be a means by which control itself may be systematically interrogated and enhanced, first by identifying circuits underlying control over voice-hearing experiences, and then using noninvasive techniques like neurofeedback to specifically alter activity in these networks in individuals without control abilities. Measuring how individuals exert control is crucial for the identification of 
participants capable of demonstrating direct, voluntary control over the onset and offset of voices in the scanner in an effort to identify circuits underlying these abilities. This information can then be leveraged for future brain-based therapeutic approaches.

This work has some limitations. First, only $22 \%$ of the participants reported a psychotic-spectrum diagnosis, although the analyses indicate a similar performance across clinical and non-clinical voicehearers even in this limited sample. Second, the sample was skewed toward females. This bias has been consistently observed in other studies with predominantly non-clinical voice-hearers ${ }^{57}$. Previous studies have described sex differences in symptomatology ${ }^{58}$ and functioning ${ }^{59}$ in voice-hearers, although goldstandard measures have shown measurement invariance across $\operatorname{sex}^{60,61}$. Future studies should similarly assess for measurement invariance of the COPE scales between sexes.

The current study contributes to the growing body of psychological ${ }^{8,13,15}$, computational ${ }^{62-65}$, and neuroimaging-based ${ }^{66}$ research that contends with the historical view and common conception that hallucinations are impenetrable to voluntary control ${ }^{67}$. The fact that hallucinations may be susceptible to voluntary influence challenges strict modularist conceptualizations of perception as informationally encapsulated from cognition ${ }^{68}$. An understanding of the neural dynamics leading to a meaningful topdown modulation of perceptual systems by higher-level cognition could lead not only to new therapeutic approaches based upon these manipulations, but the development of technologies meant to augment human perceptual capabilities writ large. Thus, reliable identification of individuals capable of voluntary control over perceptual events may be a step toward not only treatment for hallucinations, but a shift in our ability to understand and manipulate perception. 


\section{Acknowledgments}

The authors would like to thank all participants who gave generously of their time to help ensure the rigor and construct validity of the measures developed. We would also like to thank all members of the Yale COPE Advisory Committee (SPIRIT Alliance), whose advocacy and creativity was crucial for the success

of this project. Lastly, we would like to especially acknowledge the talents and legacy of Phran Ginsburg, whose early adoption of our efforts helped pave the way for a new alliance between those living with extraordinary experiences and those who seek to understand their neural bases and clinical utility. 


\section{References}

1. Daalman, K. et al. The same or different? A phenomenological comparison of auditory verbal hallucinations in healthy and psychotic individuals. J. Clin. Psychiatry 72, 320-325 (2011).

2. Beavan, V., Read, J. \& Cartwright, C. The prevalence of voice-hearers in the general population: a literature review. J. Ment. Health 20, 281-292 (2011).

3. van Os, J., Linscott, R. J., Myin-Germeys, I., Delespaul, P. \& Krabbendam, L. A systematic review and meta-analysis of the psychosis continuum: evidence for a psychosis proneness-persistenceimpairment model of psychotic disorder. Psychol. Med. 39, 179-195 (2009).

4. Morrison, A. P., Wells, A. \& Nothard, S. Cognitive and emotional predictors of predisposition to hallucinations in non-patients. Br. J. Clin. Psychol. 41, 259-270 (2002).

5. Morrison, A. P., Nothard, S., Bowe, S. E. \& Wells, A. Interpretations of voices in patients with hallucinations and non-patient controls: a comparison and predictors of distress in patients. Behav. Res. Ther. 42, 1315-1323 (2004).

6. Chandwick, P., Lees, S. \& Birchwood, M. The revised Beliefs About Voices Questionnaire (BAVQR). Br. J. Psychiatry 177, 229-232 (2000).

7. Birchwood, M., Meaden, A., Trower, P., Gilbert, P. \& Plaistow, J. The power and omnipotence of voices: subordination and entrapment by voices and significant others. Psychol. Med. 30, 337-344 (2000).

8. Swyer, A. \& Powers, A. R., 3rd. Voluntary control of auditory hallucinations: phenomenology to therapeutic implications. NPJ Schizophr 6, 19 (2020).

9. Falloon, I. R. \& Talbot, R. E. Persistent auditory hallucinations: coping mechanisms and implications for management. Psychol. Med. 11, 329-339 (1981).

10. Bentall, R. P., Haddock, G. \& Slade, P. D. Cognitive behavior therapy for persistent auditory hallucinations: From theory to therapy. Behavior Therapy vol. 25 51-66 (1994).

11. Taylor, G. \& Murray, C. A qualitative investigation into non-clinical voice hearing: what factors 
may protect against distress? Mental Health, Religion \& Culture vol. 15 373-388 (2012).

12. Roxburgh, E. C. \& Roe, C. A. A survey of dissociation, boundary-thinness, and psychological wellbeing in spiritualist mental mediumship. J. Parapsychol. 75, (2011).

13. Roxburgh, E. C. \& Roe, C. A. Reframing voices and visions using a spiritual model. An interpretative phenomenological analysis of anomalous experiences in mediumship. Mental Health, Religion \& Culture vol. 17 641-653 (2014).

14. Powers, A. R., III, Kelley, M. S. \& Corlett, P. R. Varieties of Voice-Hearing: Psychics and the Psychosis Continuum. Schizophr Bull 43, 84-98 (2017).

15. Mourgues, C. et al. Development of Voluntary Control Over Voice-Hearing Experiences: Evidence From Treatment-Seeking and Non-Treatment-Seeking Voice-Hearers. Schizophr Bull Open 1, sgaa052 (2020).

16. Wei, Y. et al. Functional magnetic resonance imaging in a single schizophrenia patient with voluntary control over auditory verbal hallucinations. Schizophrenia Research vol. 215 465-466 (2020).

17. Haddock, G., McCarron, J., Tarrier, N. \& Faragher, E. B. Scales to measure dimensions of hallucinations and delusions: the psychotic symptom rating scales (PSYRATS). Psychol. Med. 29, 879-889 (1999).

18. Larøi, F. How do auditory verbal hallucinations in patients differ from those in non-patients? Front. Hum. Neurosci. 6, 25 (2012).

19. Baumeister, D., Sedgwick, O., Howes, O. \& Peters, E. Auditory verbal hallucinations and continuum models of psychosis: A systematic review of the healthy voice-hearer literature. Clin. Psychol. Rev. 51, 125-141 (2017).

20. de Leede-Smith, S. \& Barkus, E. A comprehensive review of auditory verbal hallucinations: lifetime prevalence, correlates and mechanisms in healthy and clinical individuals. Front. Hum. Neurosci. 7, 367 (2013).

21. Daalman, K., Sommer, I. E., Derks, E. M. \& Peters, E. R. Cognitive biases and auditory verbal 
hallucinations in healthy and clinical individuals. Psychol. Med. 43, 2339-2347 (2013).

22. Woods, A., Jones, N., Alderson-Day, B., Callard, F. \& Fernyhough, C. Experiences of hearing voices: analysis of a novel phenomenological survey. Lancet Psychiatry 2, 323-331 (2015).

23. Waters, F. et al. Auditory hallucinations in schizophrenia and nonschizophrenia populations: a review and integrated model of cognitive mechanisms. Schizophr. Bull. 38, 683-693 (2012).

24. Moseley, P. et al. Correlates of hallucinatory experiences in the general population: an international multi-site replication study. doi:10.31234/osf.io/4wbgc.

25. Dodgson, G. et al. Tailoring cognitive behavioural therapy to subtypes of voice-hearing using a novel tabletised manual: a feasibility study. Behavioural and Cognitive Psychotherapy vol. 49 287$301(2021)$.

26. Bartels-Velthuis, A. A., van de Willige, G., Jenner, J. A. \& Wiersma, D. Consistency and reliability of the auditory vocal hallucination rating scale (AVHRS). Epidemiol. Psychiatr. Sci. 21, 305-310 (2012).

27. Kern, B., Axelrod, J., Gao, Y. \& Keedy, S. Exchange the magnifying glass for a microscope: The Chicago hallucination assessment Tool (CHAT). vol. 41 (OXFORD UNIV PRESS GREAT CLARENDON ST, OXFORD OX2 6DP, ENGLAND, 2015).

28. Willis, G. B. Cognitive Interviewing: A Tool for Improving Questionnaire Design. (SAGE Publications, 2004).

29. Harris, P. A. et al. Research electronic data capture (REDCap)--a metadata-driven methodology and workflow process for providing translational research informatics support. J. Biomed. Inform. 42, $377-381$ (2009).

30. Harris, P. A. et al. The REDCap consortium: Building an international community of software platform partners. J. Biomed. Inform. 95, 103208 (2019).

31. Chesterman, L. P., Paul Chesterman, L., Terbeck, S. \& Vaughan, F. Malingered psychosis. Journal of Forensic Psychiatry \& Psychology vol. 19 275-300 (2008).

32. Resnick, P. J. THE DETECTION OF MALINGERED PSYCHOSIS. Psychiatric Clinics of North 
America vol. 22 159-172 (1999).

33. Stephane, M., Pellizzer, G., Roberts, S. \& McClannahan, K. Computerized binary scale of auditory speech hallucinations (cbSASH). Schizophr. Res. 88, 73-81 (2006).

34. Resnick, P. J. \& Knoll, J. L., IV. Malingered psychosis. (2018).

35. Peters, E. R., Joseph, S. A. \& Garety, P. A. Measurement of delusional ideation in the normal population: introducing the PDI (Peters et al. Delusions Inventory). Schizophr. Bull. 25, 553-576 (1999).

36. Chadwick, P., Lees, S. \& Birchwood, M. The revised Beliefs About Voices Questionnaire (BAVQR). British Journal of Psychiatry vol. 177 229-232 (2000).

37. Launay, G. \& Slade, P. The measurement of hallucinatory predisposition in male and female prisoners. Personality and Individual Differences vol. 2 221-234 (1981).

38. Wegner, D. M. \& Zanakos, S. Chronic Thought Suppression. Journal of Personality vol. 62 615-640 (1994).

39. Brantley, P. J., Waggoner, C. D., Jones, G. N. \& Rappaport, N. B. A Daily Stress Inventory: development, reliability, and validity. J. Behav. Med. 10, 61-74 (1987).

40. Stevanovic, D. Quality of Life Enjoyment and Satisfaction Questionnaire-short form for quality of life assessments in clinical practice: a psychometric study. J. Psychiatr. Ment. Health Nurs. 18, 744750 (2011).

41. Kroenke, K., Spitzer, R. L. \& Williams, J. B. The PHQ-9: validity of a brief depression severity measure. J. Gen. Intern. Med. 16, 606-613 (2001).

42. Hoffman, R. E. et al. Temporoparietal transcranial magnetic stimulation for auditory hallucinations: safety, efficacy and moderators in a fifty patient sample. Biol. Psychiatry 58, 97-104 (2005).

43. Wu, H. \& Leung, S.-O. Can Likert Scales be Treated as Interval Scales?-A Simulation Study. Journal of Social Service Research vol. 43 527-532 (2017).

44. Li, C.-H. Confirmatory factor analysis with ordinal data: Comparing robust maximum likelihood and diagonally weighted least squares. Behav. Res. Methods 48, 936-949 (2016). 
45. Beavers, A. S. et al. Practical Considerations for Using Exploratory Factor Analysis in Educational Research. Practical Assessment, Research, and Evaluation 18, 6 (2013).

46. Kline, R. B. Principles and Practice of Structural Equation Modeling. (Guilford Press, 2011).

47. Zhang, Z. \& Yuan, K.-H. Robust Coefficients Alpha and Omega and Confidence Intervals With Outlying Observations and Missing Data: Methods and Software. Educ. Psychol. Meas. 76, 387-411 (2016).

48. Preti, A. et al. The psychometric discriminative properties of the Peters et al Delusions Inventory: a receiver operating characteristic curve analysis. Compr. Psychiatry 48, 62-69 (2007).

49. Hirano, Y. \& Tamura, S. Recent findings on neurofeedback training for auditory hallucinations in schizophrenia. Curr. Opin. Psychiatry (2021) doi:10.1097/YCO.0000000000000693.

50. Thakkar, K. N., Mathalon, D. H. \& Ford, J. M. Reconciling competing mechanisms posited to underlie auditory verbal hallucinations. Philos. Trans. R. Soc. Lond. B Biol. Sci. 376, 20190702 (2021).

51. Humpston, C. et al. Real-Time Functional Magnetic Resonance Imaging Neurofeedback for the Relief of Distressing Auditory-Verbal Hallucinations: Methodological and Empirical Advances. Schizophr. Bull. 46, 1409-1417 (2020).

52. Corstens, D., Longden, E., McCarthy-Jones, S., Waddingham, R. \& Thomas, N. Emerging perspectives from the hearing voices movement: implications for research and practice. Schizophr. Bull. 40 Suppl 4, S285-94 (2014).

53. Birchwood, M., Mason, R., MacMillan, F. \& Healy, J. Depression, demoralization and control over psychotic illness: a comparison of depressed and non-depressed patients with a chronic psychosis. Psychol. Med. 23, 387-395 (1993).

54. Niles, H. F., Walsh, B. C., Woods, S. W. \& Powers, A. R., Iii. Does hallucination perceptual modality impact psychosis risk?

55. Orlov, N. D. et al. Real-time fMRI neurofeedback to down-regulate superior temporal gyrus activity in patients with schizophrenia and auditory hallucinations: a proof-of-concept study. Transl. 
Psychiatry 8, 46 (2018).

56. Fovet, T. et al. Translating Neurocognitive Models of Auditory-Verbal Hallucinations into Therapy: Using Real-time fMRI-Neurofeedback to Treat Voices. Front. Psychiatry 7, 103 (2016).

57. Lawrence, C., Jones, J. \& Cooper, M. Hearing Voices in a Non-Psychiatric Population. Behavioural and Cognitive Psychotherapy vol. 38 363-373 (2010).

58. Rosen, M., Haidl, T. K., Ruhrmann, S., Vogeley, K. \& Schultze-Lutter, F. Sex differences in symptomatology of psychosis-risk patients and in prediction of psychosis. Archives of Women's Mental Health vol. 23 339-349 (2020).

59. Usall, J. et al. Influence of gender on social outcome in schizophrenia. Acta Psychiatrica Scandinavica vol. 106 337-342 (2002).

60. Hayashi, N., Igarashi, Y., Yamashina, M. \& Suda, K. Is There a Gender Difference in a Factorial Structure of the Positive and Negative Syndrome Scale? Psychopathology vol. 35 28-35 (2002).

61. Rodríguez-Testal, J. F. et al. Spanish validation of the self-evaluation of negative symptoms scale SNS in an adolescent population. BMC Psychiatry vol. 19 (2019).

62. Friston, K. J. Hallucinations and perceptual inference. Behav. Brain Sci. 28, 764-+ (2005).

63. Powers, A. R., Iii, Kelley, M. \& Corlett, P. R. Hallucinations as Top-Down Effects on Perception. Biological Psychiatry: Cognitive Neuroscience and Neuroimaging 1, 393-400 (2016).

64. Howe, P. D. \& Carter, O. L. Hallucinations and mental imagery demonstrate top-down effects on visual perception. Behav. Brain Sci. 39, e248 (2016).

65. Corlett, P. R. et al. Hallucinations and Strong Priors. Trends Cogn. Sci. 23, (2019).

66. Powers, A. R., Mathys, C. \& Corlett, P. R. Pavlovian conditioning-induced hallucinations result from overweighting of perceptual priors. Science 357, 596-600 (2017).

67. Slade, P. D. \& Bentall, R. P. Sensory deception : a scientific analysis of hallucination. x, 275 p. (Johns Hopkins University Press, 1988).

68. Firestone, C. \& Scholl, B. J. Can you experience 'top-down' effects on perception?: The case of race categories and perceived lightness. Psychon. Bull. Rev. 22, 694-700 (2015). 


\section{Figure Legends}

Figure 1. Scale development. Starting with a literature review and qualitative study around control over voice-hearing experiences, a panel of experts composed of healthcare professionals, members of spiritual communities, and members of the Hearing Voices Network subsequently developed 59 items meant to capture control over voice-hearing experiences. These were tested by a panel of 52 voice-hearers, and 35 items were retained. Exploratory and confirmatory factor analyses were performed on the items meant to capture degree of control and approaches used to exert control.

Figure 2. Psychometrics. A. Scree plot for Degree of Control and Methods of Control items at time of voice onset and at the present. Solid line demarcates eigenvalue $=1 . \mathrm{PC}=$ data derived from Principal Components Analysis; FA = data derived from Factor Analysis. B. CFA for methods of control. Factor loadings $(\lambda)$ for both time points are reported. Ordinal coefficient $(\omega)$ was used to compute scale internal consistency. Fit indices (at present): $X^{2}(34)=104.607, \mathrm{p}<.001 ; \mathrm{CFI}=.988 ; \mathrm{TLI}=.984 ; \mathrm{RMSEA}=.111$ $(95 \% \mathrm{CI}=.87-11) ; \mathrm{SRMR}=.097 . \mathrm{C} . \mathrm{CFA}$ for Degree of Control. As in B, factor loadings for both time points are reported and $\omega$ provides a measure of internal consistency. Fit indices: at present, $X^{2}(20)=$ 15.805, $\mathrm{p}<.001 ; \mathrm{CFI}=.998 ; \mathrm{TLI}=.995 ; \mathrm{RMSEA}=.081(95 \% \mathrm{CI}=.046-115) ; \mathrm{SRMR}=.028 ;$ at voice onset, $X^{2}(20)=45.809, \mathrm{p}<.001 ; \mathrm{CFI}=.993 ; \mathrm{TLI}=.990 ; \mathrm{RMSEA}=.087(95 \% \mathrm{CI}=.057-120) ; \mathrm{SRMR}$ $=.042$.

\section{Figure 3. Voice characteristics and control in individuals with and without a psychotic-spectrum}

diagnosis. A. Selected phenomenological characteristics of voices, derived from the computerized binary Scale for Auditory Speech Hallucinations (cbSASH), as endorsed by individuals with (blue) and without (green) a psychotic-spectrum diagnosis. Note minor differences in acoustic characteristics and several predominating differences in affective response and strategies used to exert control over voices. ***, ${ }^{*}<$ 0.001. B. Correlations of scores on each sub-scale, split between those with (blue) and without (green) a psychotic-spectrum diagnosis. Relationships among the variables do not differ based on diagnosis. $\mathbf{C}$. 
Distribution of average item ratings per scale at voice onset and present time, split by presence of psychotic-spectrum diagnosis. D. Average item ratings at the present (solid) and at time of voice onset (hashed), split by diagnostic category (blue / green). **, $\mathrm{p}<0.01$.

Figure 4. Structural equation model of relationship between beliefs about voices, degree of control, and quality of life. Beliefs about voices' malevolence, measured by the Beliefs about Voices Questionnaire, Malevolence subscale (BAVQ-M), negatively predicts both degree of control and quality of life (QOL). Degree of control positively predicts quality of life and results in a decreased amount of variance explained by malevolence beliefs. *, p < $0.05 ; * * *, p<0.001$. 


\begin{tabular}{|c|c|c|c|c|c|c|c|}
\hline \multirow{2}{*}{\multicolumn{2}{|c|}{$\begin{array}{l}\text { Table 1. Self-Reported Diagnosis } \\
\text { Diagnosis }\end{array}$}} & \multicolumn{2}{|c|}{$\begin{array}{c}\text { EFA } \\
\text { Subsample }\end{array}$} & \multicolumn{2}{|c|}{$\begin{array}{c}\text { CFA } \\
\text { Subsample }\end{array}$} & \multicolumn{2}{|c|}{ Total Sample } \\
\hline & & Frq & $\%$ & Frq & $\%$ & Frq & $\%$ \\
\hline \multicolumn{8}{|l|}{ Most frequently reported diagnosis } \\
\hline Anxiety & & 25 & 16.89 & 27 & 15.88 & 54 & 16.98 \\
\hline Depression & & 26 & 17.57 & 25 & 14.71 & 48 & 15.09 \\
\hline Post Traumatic Stress Disorder & & 11 & 7.43 & 13 & 7.65 & 23 & 7.23 \\
\hline Borderline Personality Disorder & & 8 & 5.41 & 8 & 4.71 & 16 & 5.03 \\
\hline ADHD & & 7 & 4.73 & 5 & 2.94 & 14 & 4.40 \\
\hline Dissociative Identity Disorder & & 2 & 1.35 & 3 & 1.76 & 6 & 1.89 \\
\hline Dysthymia & & 1 & 0.68 & 1 & 0.59 & 1 & 0.31 \\
\hline Major Depression & & 1 & 0.68 & 8 & 4.71 & 12 & 3.77 \\
\hline Obsessive Compulsive Disorder & & 4 & 2.70 & 4 & 2.35 & 9 & 2.83 \\
\hline Other Diagnosis & & 10 & 6.75 & 14 & 8.24 & 24 & 7.55 \\
\hline \multicolumn{8}{|l|}{ Psychosis-spectrum illness } \\
\hline Bipolar II & & 5 & 3.38 & 4 & 2.35 & 9 & 2.83 \\
\hline Bipolar I & & 3 & 2.03 & 2 & 1.18 & 5 & 1.57 \\
\hline Bipolar Unspecified & & 10 & 6.76 & 8 & 4.71 & 18 & 5.66 \\
\hline Paranoid Schizophrenia & & 1 & 0.68 & 1 & 0.59 & 2 & 0.63 \\
\hline Psychosis & & 6 & 4.05 & 6 & 3.53 & 12 & 3.77 \\
\hline Schizophrenia & & 2 & 1.35 & 6 & 3.53 & 8 & 2.52 \\
\hline Schizoaffective Disorder & & 8 & 5.41 & 10 & 5.88 & 18 & 5.66 \\
\hline Total Psychotic-like spectrum & & 35 & 23.65 & 37 & 21.76 & 72 & 22.64 \\
\hline \multicolumn{8}{|c|}{ Total Reported Psychiatric Diagnosis } \\
\hline & 0 & 76 & 51.40 & 91 & 53.50 & 167 & 52.52 \\
\hline & 1 & 32 & 21.60 & 28 & 16.50 & 60 & 18.87 \\
\hline & 2 & 17 & 11.50 & 25 & 14.70 & 42 & 13.21 \\
\hline & 3 & 15 & 10.10 & 9 & 5.30 & 24 & 7.55 \\
\hline & 4 & 3 & 2.00 & 13 & 7.60 & 16 & 5.03 \\
\hline & 5 & 3 & 2.00 & 1 & 0.60 & 4 & 1.26 \\
\hline & 6 & 2 & 1.40 & 3 & 1.80 & 5 & 1.57 \\
\hline \multicolumn{8}{|l|}{ Personality Disorders (SCID-II) } \\
\hline Avoidant & & 22 & 14.86 & 14 & 8.24 & 36 & 11.32 \\
\hline Dependent & & 4 & 2.70 & 1 & 0.59 & 5 & 1.57 \\
\hline Obsessive Compulsive & & 27 & 18.24 & 23 & 13.53 & 50 & 15.72 \\
\hline Passive Aggressive & & 11 & 7.43 & 8 & 4.71 & 19 & 5.97 \\
\hline Depressive & & 12 & 8.11 & 12 & 7.06 & 24 & 7.55 \\
\hline Paranoid & & 21 & 14.19 & 13 & 7.65 & 34 & 10.69 \\
\hline Schizotypal & & 56 & 37.84 & 59 & 34.71 & 115 & 36.16 \\
\hline Schizoid & & 5 & 3.38 & 3 & 1.76 & 8 & 2.52 \\
\hline Histrionic & & 1 & 0.68 & 3 & 1.76 & 4 & 1.26 \\
\hline Narcissistic & & 20 & 13.51 & 13 & 7.65 & 33 & 10.38 \\
\hline
\end{tabular}




\begin{tabular}{|c|c|c|c|c|c|}
\hline Borderline & 27 & 18.24 & 23 & 13.53 & 15.72 \\
\hline Conduct Disorder & 20 & 13.51 & 5 & 2.94 & 7.86 \\
\hline
\end{tabular}

Note: All the diagnoses listed were self reported by the COPE participants. Personality Disorders (SCIDII) cut-offs for each diagosses were used to compute their frequencies. 
Table 2. Pearson correlation between COPE scales and administered questionnaires

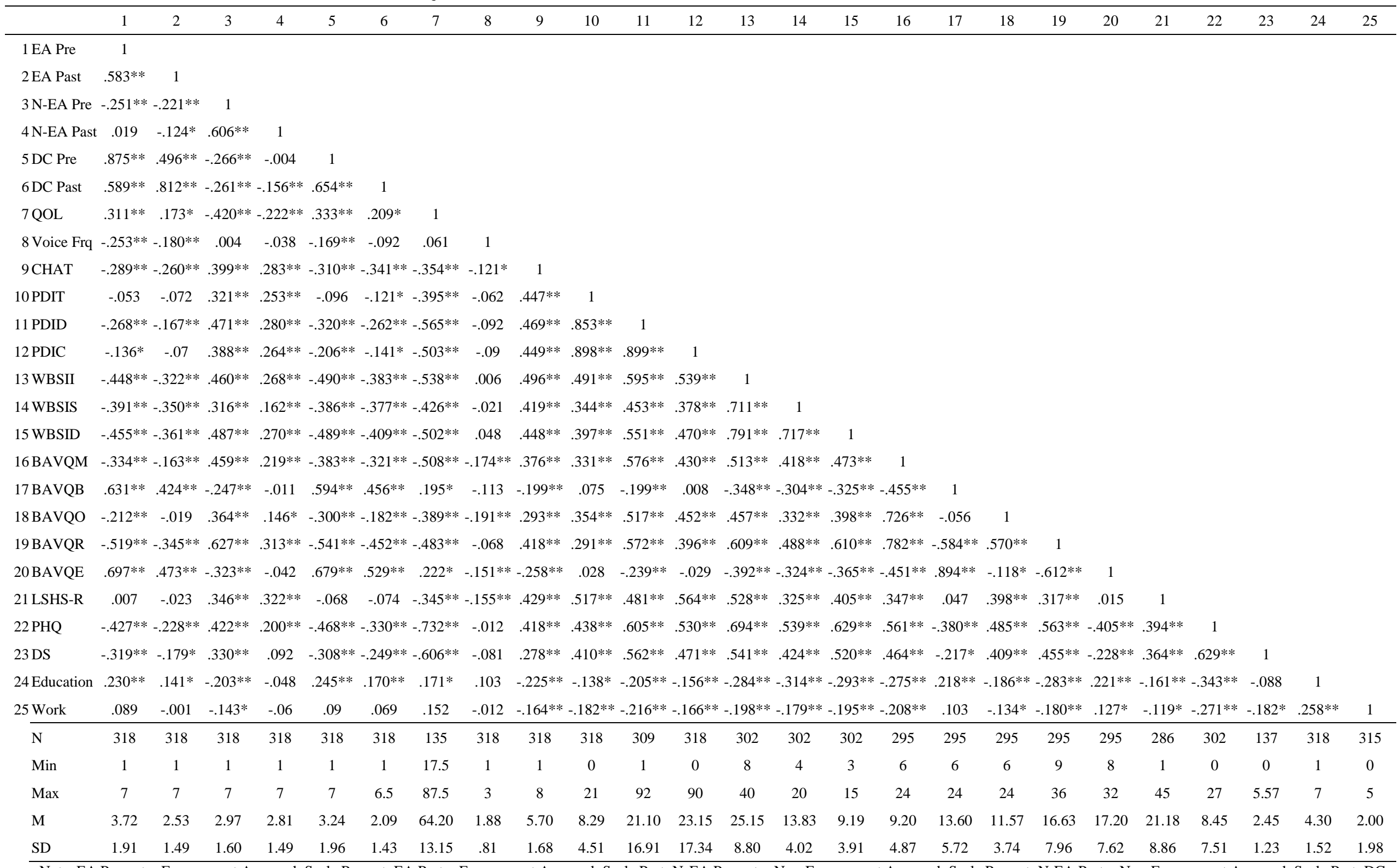

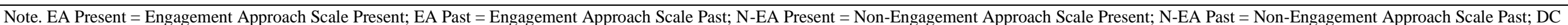

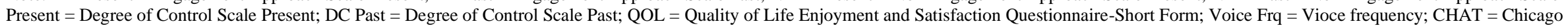

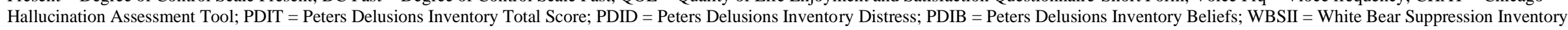

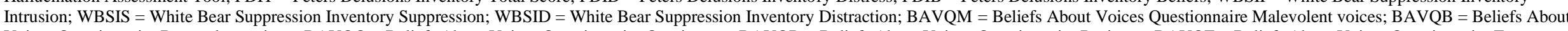

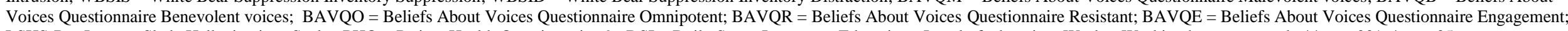

LSHS-R = Launay-Slade Hallucinations Scale; PHQ = Patient Health Questionnaire-9; DSI = Daily Stress Inventory; Education= Level of education; Work $=$ Working hours per week. ** $\mathrm{p}<.001, * \mathrm{p}<.05$. 



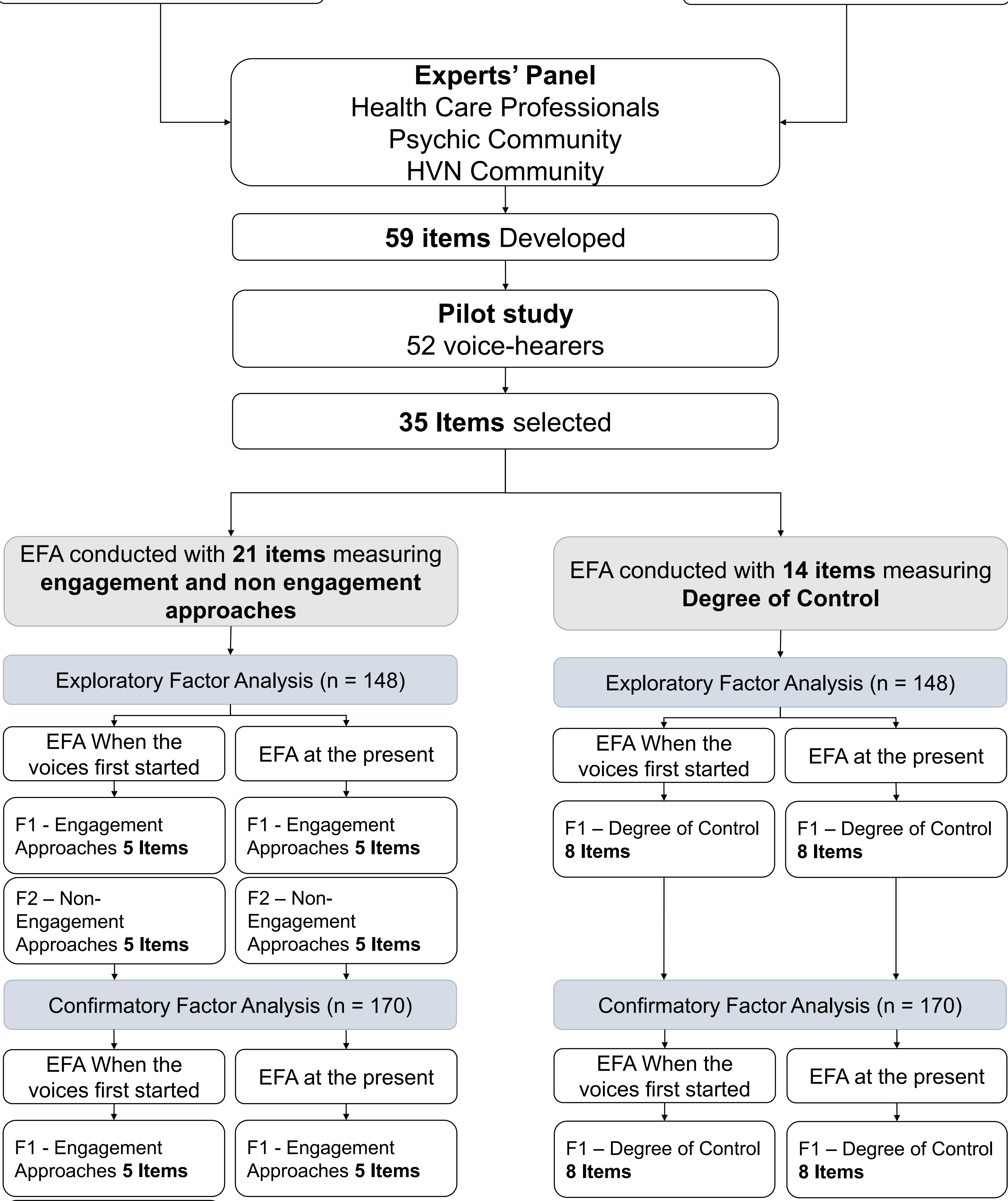

F2 - Non-

Engagement

Approaches $\mathbf{5}$ Items
F2 - Non-

Engagement

Approaches 5 Items 
At Voice Onset At the Present D

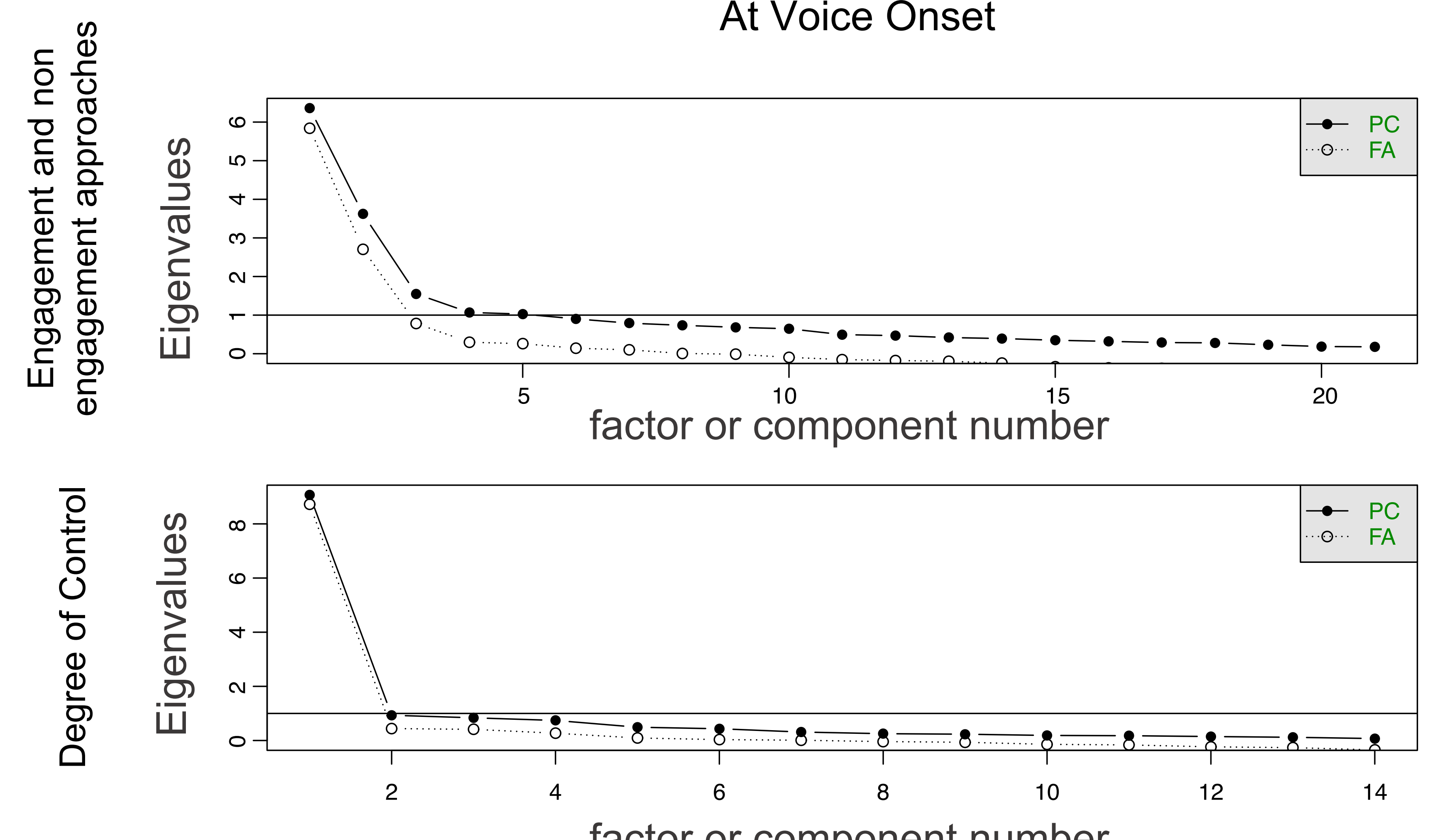
factor or component number

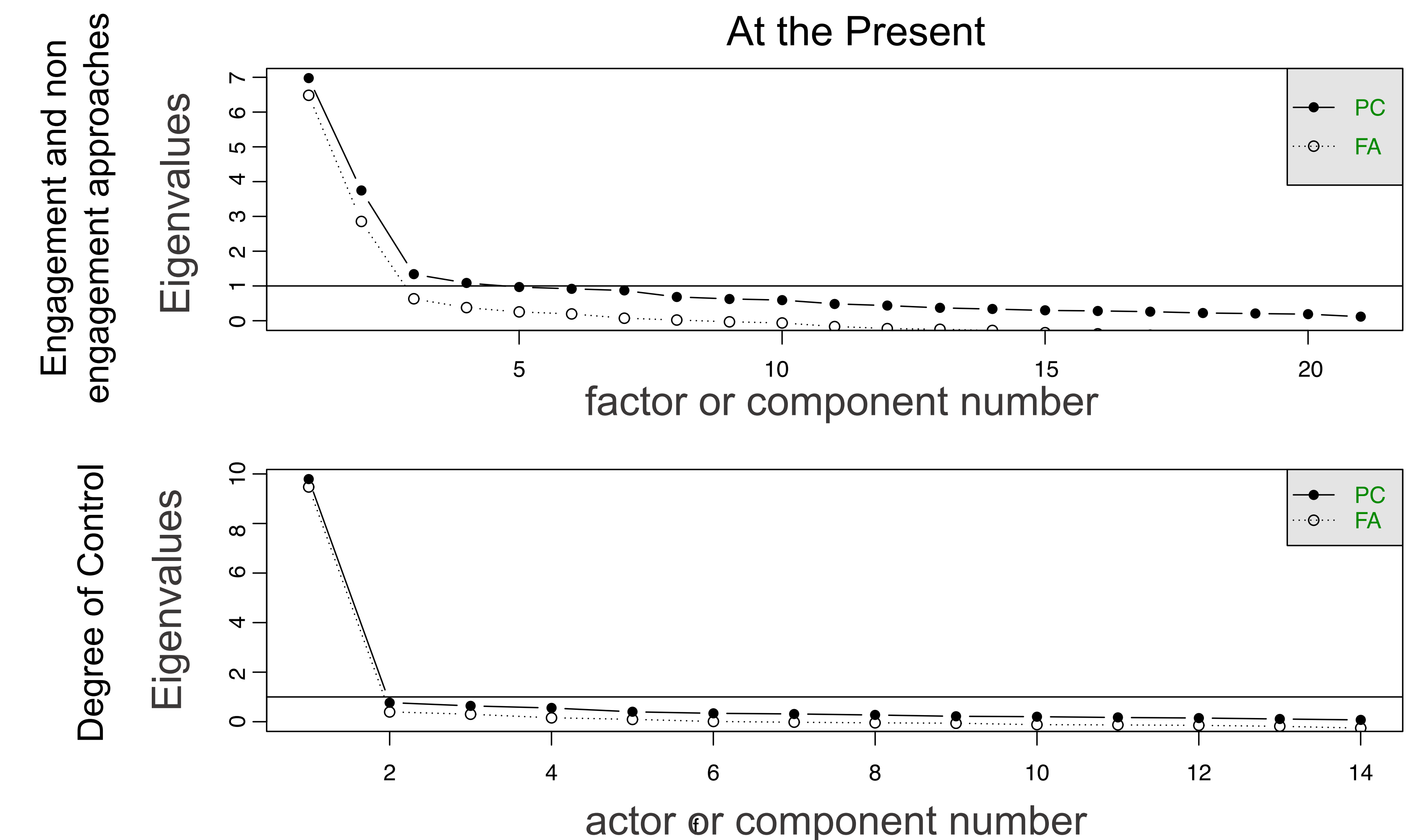

actor or component number

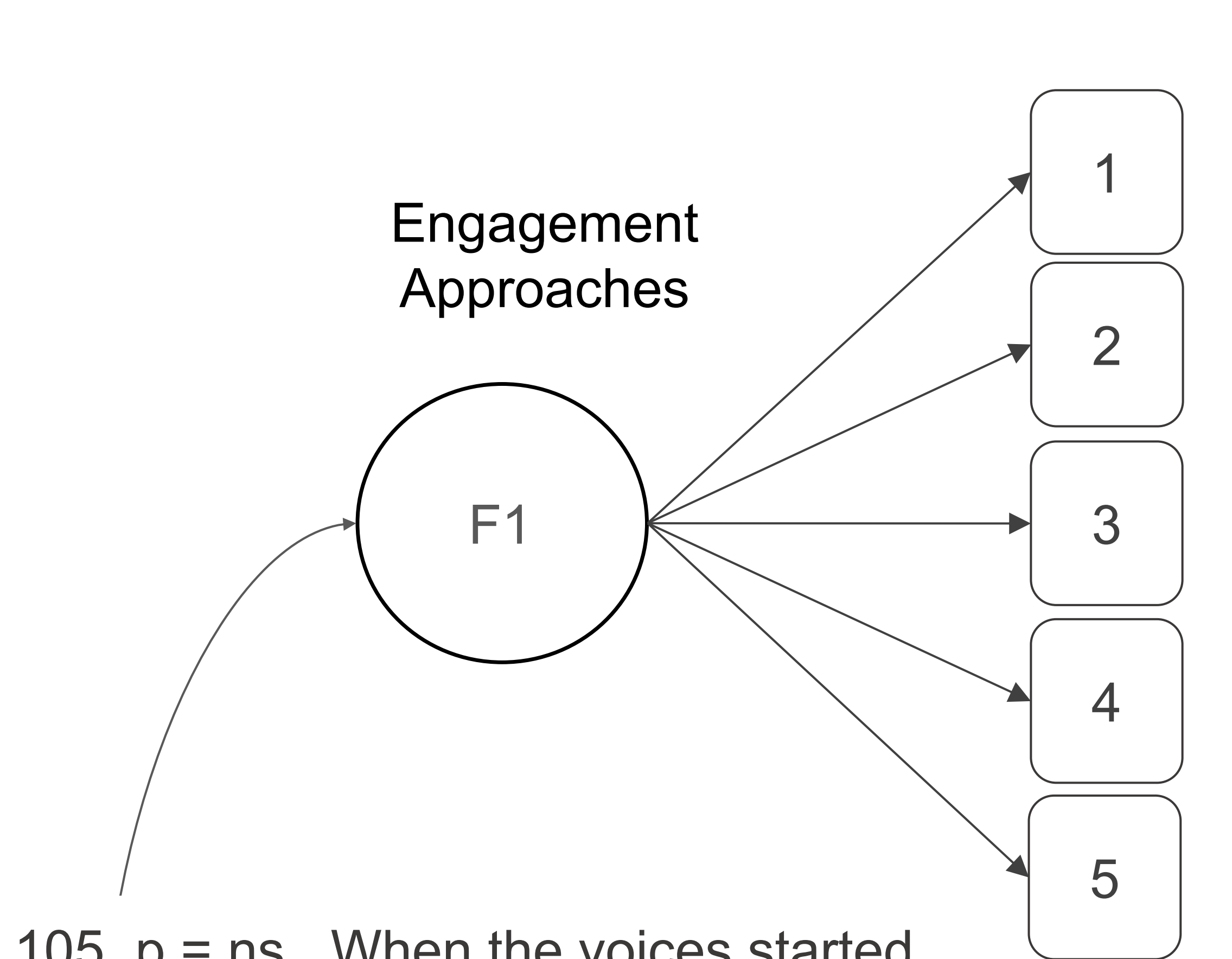

$105, p=n s$, When the voices started

Omega $\omega \quad .85(.82-.89)$

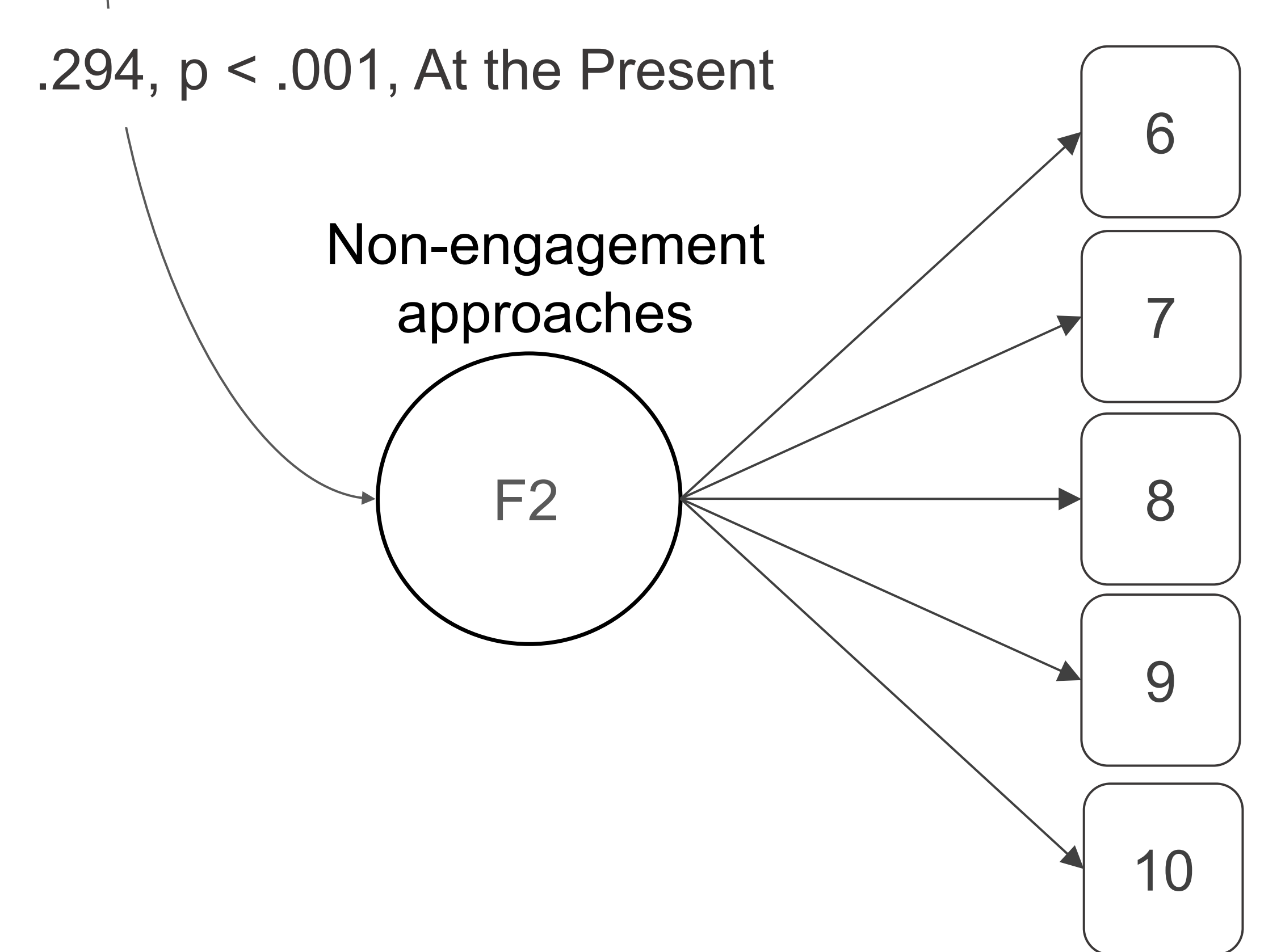

$\lambda$

850

803

.965

.842

.812

.745

.843

765

.714

.517

.848
At Voice Onset At the Present

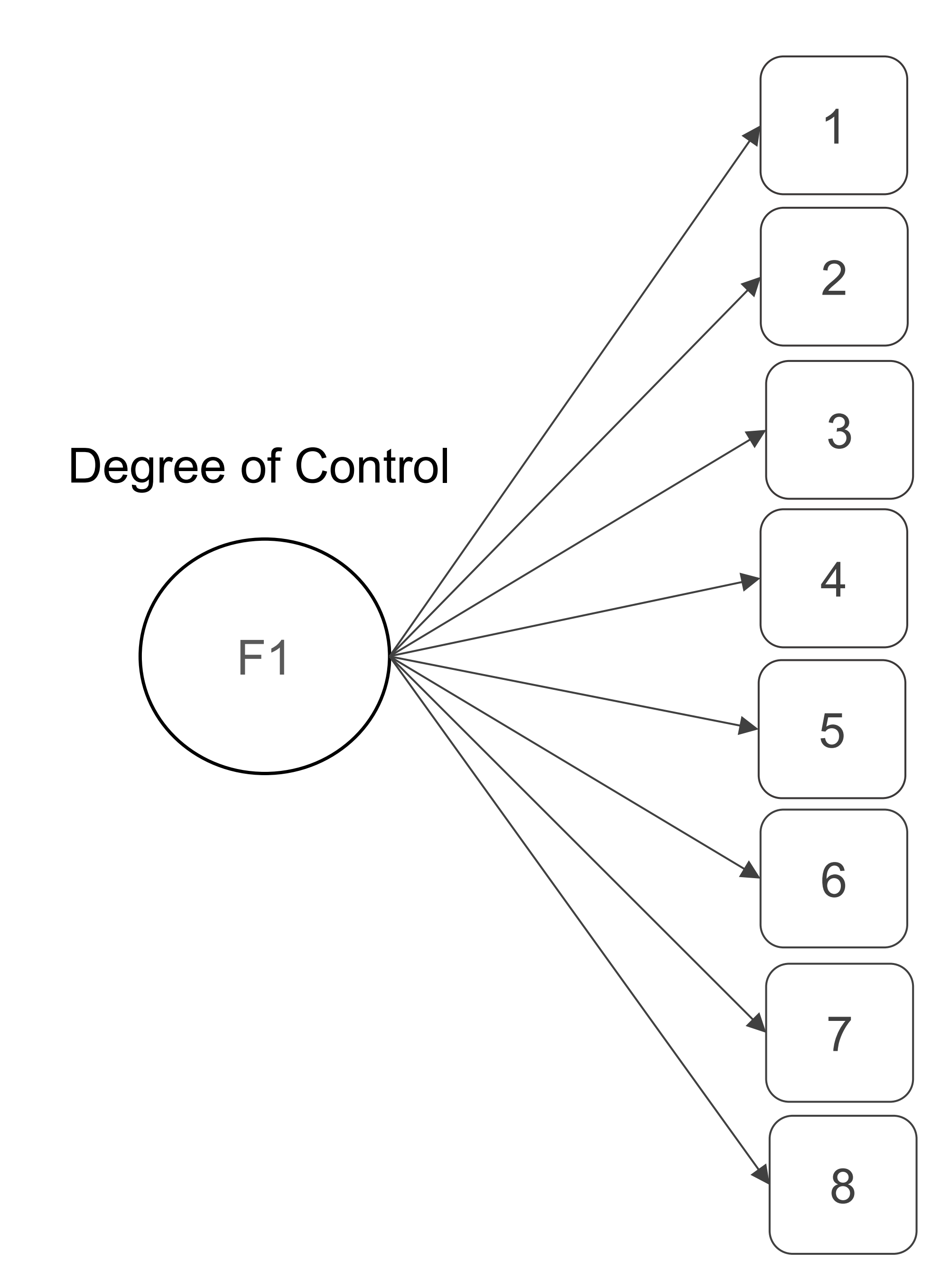

$\lambda$

$\lambda$

$.884 \quad .887$

782

.823

.822

$929 \quad .921$

.879

.914

.898

.899

Omega $\omega$ 


\begin{tabular}{|c|c|}
\hline & Hearing voices is like thinking ${ }^{\star \star \star}$ \\
\hline & The voices are louder than normal conversations ${ }^{* *}$ \\
\hline & The voices are as loud as normal conversations \\
\hline & The loudness of the voices changes over time ${ }^{\star \star \star}$ \\
\hline & The voices have volume (loudness) \\
\hline & I can not make out the sex of the voices \\
\hline & The voices are deep like thoughts \\
\hline & he voices are clear like sounds \\
\hline \multirow{7}{*}{ 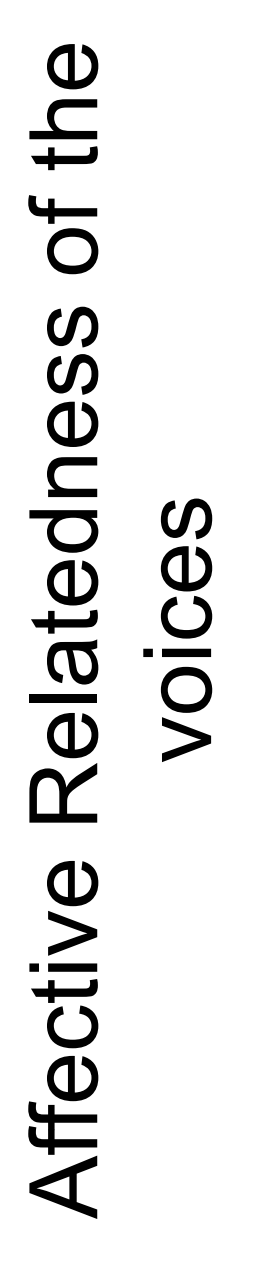 } & I woul \\
\hline & I would miss the voices if they stopped** \\
\hline & The voices I hear are bothersome** \\
\hline & The voices I hear are comforting* \\
\hline & I am not bothered by the voices* \\
\hline & I would be happy if I stopped hearing voices* \\
\hline & \\
\hline \multirow{4}{*}{ 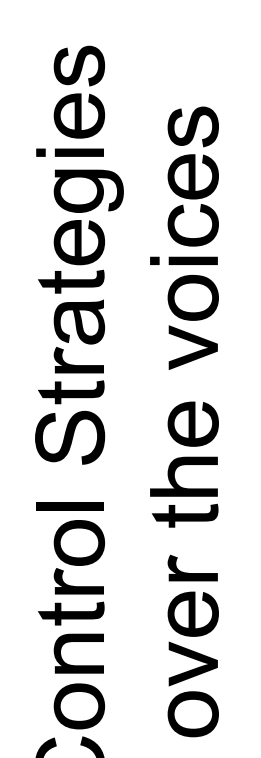 } & I do things to stop or decrease the voices* \\
\hline & I listen to sounds to stop or decrease the voices ${ }^{* * *}$ \\
\hline & I listen to someone to stop or decrease the voices ${ }^{* *}$ \\
\hline & \\
\hline
\end{tabular}

B

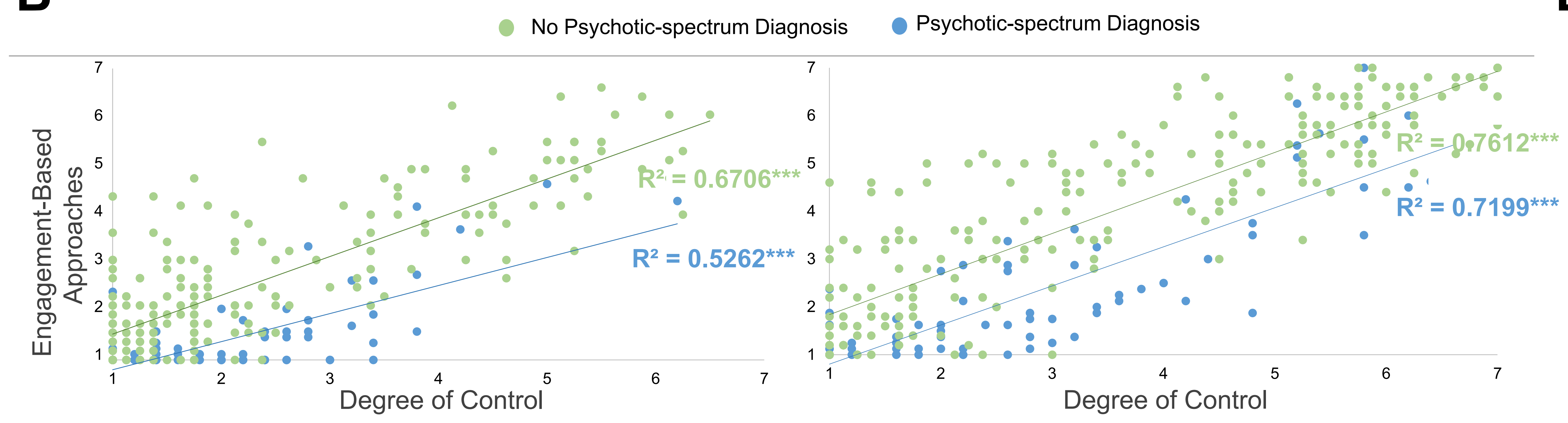

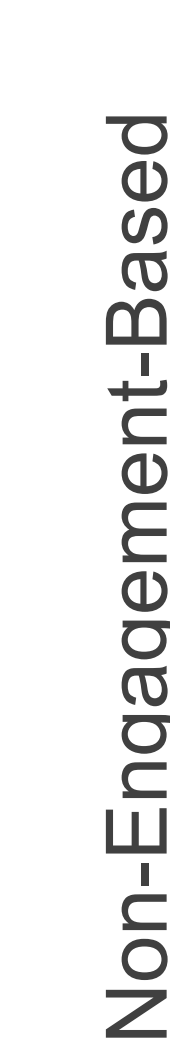
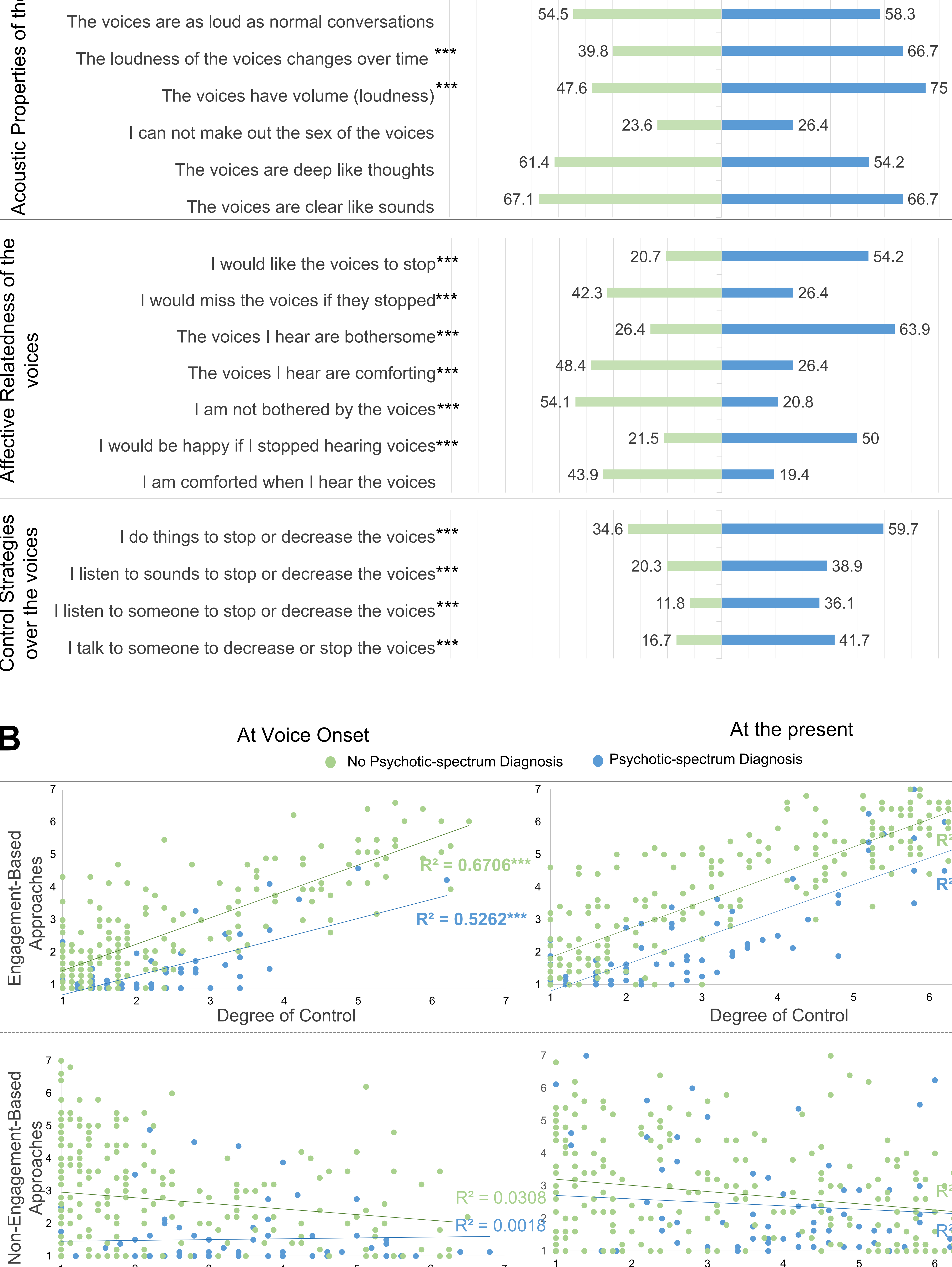

61.4

67.1

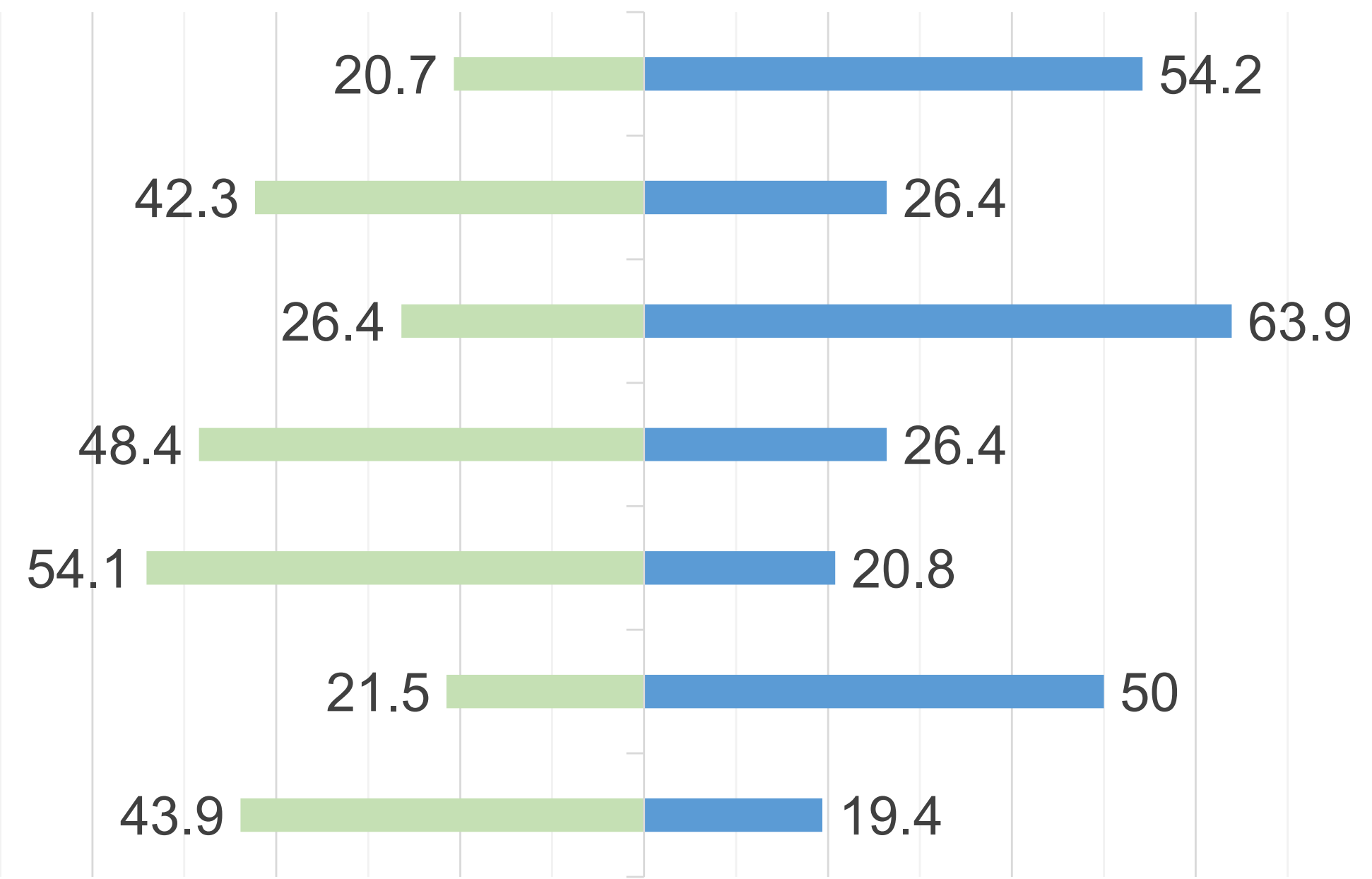

59.7

At the present

D

.

8
7
6
5
4
3
2
1
0


8
7
6
5
4
3
2
1
0

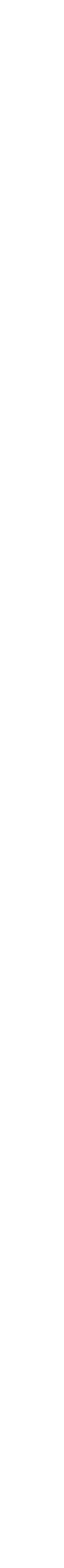

\section{Non-Engagement-Based Approaches}
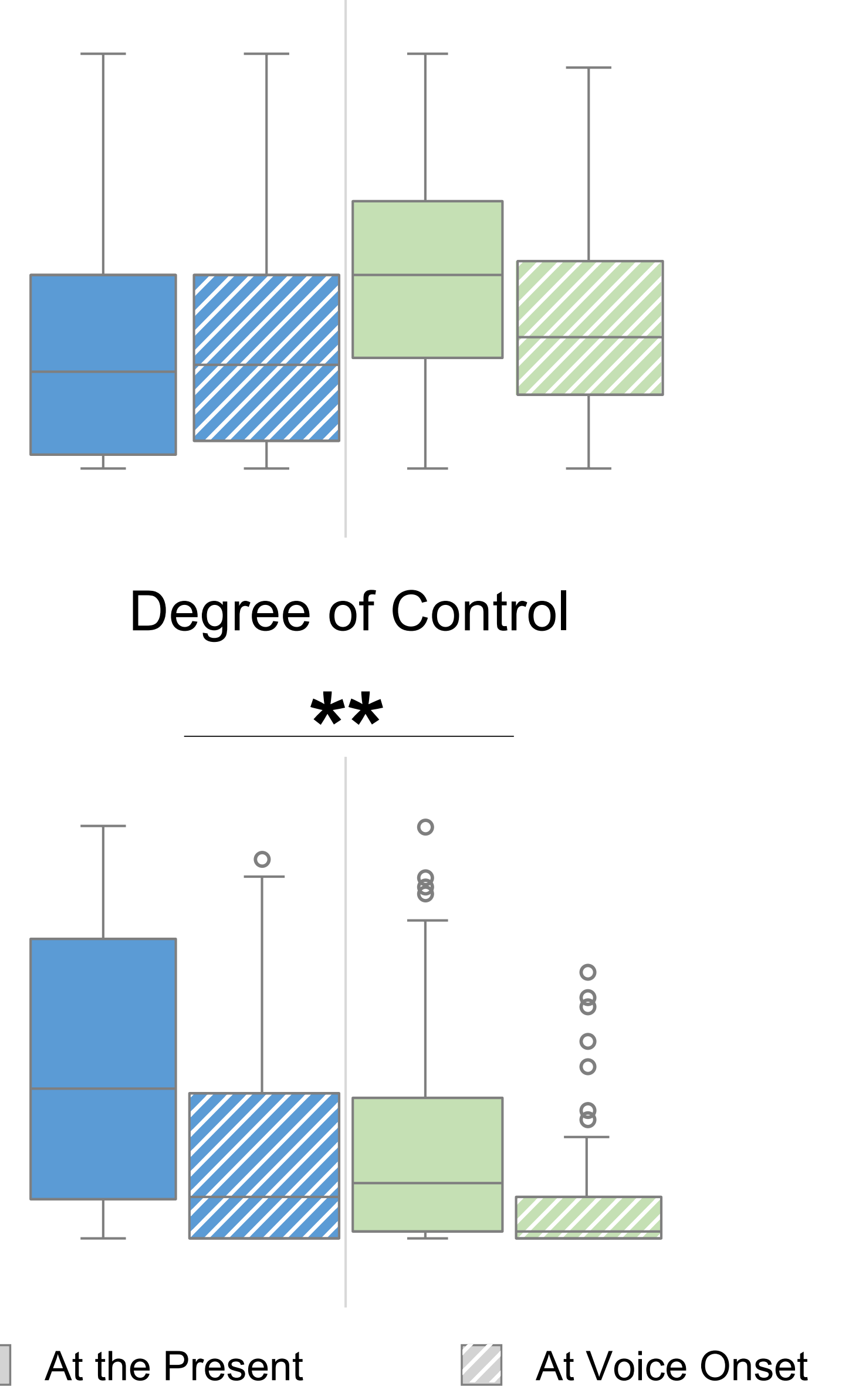
